\title{
COMPOSIÇÃO MINERAL DO RIZOMA E RAIZ EM PLANTAS DE Strelitzia augusta SOB DEFICIÊNCIAS DE MACRONUTRIENTES
}

\author{
COELHO, Viviane Amaral Toledo ${ }^{1}$ \\ SOUZA, Carla Giselly de ${ }^{2}$ \\ NASCIMENTO, Ednardo Souza de ${ }^{3}$ \\ LACERDA, Luiza Gobira ${ }^{4}$ \\ CARDOSO, Patrícia Alves ${ }^{5}$
}

\begin{abstract}
RESUMO: O objetivo foi avaliar o teor e acúmulo nutricionais do rizoma e raiz de plantas de Strelitzia augusta, em solução nutritiva, sob deficiência de macronutrientes. O experimento foi realizado em casa de vegetação do DCS/UFLA, Lavras-MG. O esquema estatístico utilizado foi o DIC com três repetições, contendo sete tratamentos, em solução nutritiva. Os tratamentos foram: solução nutritiva completa (controle) e soluções nutritivas com omissões individuais de $\mathrm{N}, \mathrm{P}, \mathrm{K}, \mathrm{Ca}, \mathrm{Mg}$ e $\mathrm{S}$. Após a germinação, as mudas foram transferidas para a solução nutritiva completa com $10 \%$ da sua força iônica (período de adaptação), as quais permaneceram com aeração constante. As plantas foram selecionadas quanto à uniformidade de tamanho e transferidas para vasos de plástico (5L) com solução nutritiva a 100\%, no qual foram aplicados os tratamentos. As plantas foram colhidas após 180 dias, sendo, posteriormente, coletada a matéria seca e realizada a análise química do rizoma e raízes das plantas. A omissão de macronutrientes afeta a produção de matéria seca do rizoma e raízes da planta bem como promovem alterações nos teores e nos acúmulos de nutrientes. As deficiências de macronutrientes causam alterações nos teores e acúmulos no rizoma e raízes dessa espécie, afetando o desempenho da planta.
\end{abstract}

Palavras-chave: Strelitzia augusta, Omissão de macronutrientes, Plantas ornamentais.

\section{MINERAL COMPOSITION OF RHIZOME AND ROOT IN Strelitzia augusta PLANTS UNDER MACRONUTRIENT DEFICIENCIES}

\begin{abstract}
SUMMARY: The objective was to evaluate the nutritional content and accumulation of the rhizome and root of Strelitzia augusta plants, in nutrient solution, under macronutrient deficiency. The experiment was carried out in a greenhouse at DCS / UFLA, Lavras - MG. The statistical scheme used was the DIC with three replications, containing seven treatments, in nutrient solution. The treatments were: complete nutrient solution (control) and nutrient solutions with individual omissions of $\mathrm{N}, \mathrm{P}, \mathrm{K}, \mathrm{Ca}, \mathrm{Mg}$ and $\mathrm{S}$. After germination, the seedlings were transferred to the complete nutrient solution with $10 \%$ of its ionic strength (adaptation period), which remained with constant aeration. The plants were selected for size uniformity and transferred to plastic pots (5L) with $100 \%$ nutrient solution, in which the treatments were applied. The plants were harvested after 180 days, after which the dry matter was collected and chemical analysis of the rhizome and roots of the plants was performed. The omission of macronutrients affects the production of dry matter from the rhizome and roots of the plant, as well as promoting changes in the contents and accumulations of nutrients. Deficiencies of macronutrients cause changes in the contents and accumulations in the rhizome and roots of this species, affecting the performance of the plant.
\end{abstract}

Keywords: Strelitzia augusta, Omission of macronutrients, Ornamental plants.

\footnotetext{
${ }^{1}$ Doutorado em Ciência do Solo pela Universidade Federal de Lavras e University of Queensland, na Austrália. Docente na Faculdade de Almenara, Almenara, Minas Gerais, Brasil.

${ }^{2}$ Doutorado em Nutrição e Produção Animal pela Universidade Federal da Paraíba e University of Queensland, Austrália e Pós-Doutoranda em Forragicultura pela Universidade Federal Rural de Pernambuco, Brasil.

${ }^{3}$ Mestre em Ciências da Saúde e Graduação em Pedagogia pela Universidade Estadual de Montes Claros. Docente na Faculdade de Alfa Almenara, Minas Gerais, Brasil.

${ }^{4}$ Especialização em Farmacologia e Interação Medicamentosas pelo Centro Universitário Internacional.

Coordenador de Curso do ALFA, Faculdade de Almenara, Almenara, Minas Gerais, Brasil.

${ }^{5}$ Mestrado em Microbiologia Agropecuária pela Universidade Estadual Paulista Júlio de Mesquita Filho, Docente da Faculdade de Almenara, Almenara, Minas Gerais, Brasil.
} 


\section{INTRODUÇÃO}

O setor de flores e plantas ornamentais no Brasil vem crescendo ao longo dos anos, tornando-se um dos segmentos do agronegócio que mais cresce na atualidade, tanto na produção de espécies temperadas quanto na de tropicais. No ano de 2014 a cadeia produtiva de flores no Brasil, movimentou R \$ 5,64 bilhões, o que correspondeu a um crescimento de $8 \%$ em relação ao ano de 2013. O crescimento deste setor pode estar relacionado ao aumento do poder aquisitivo da população brasileira, que passou a consumir mais flores e ao número de novas cultivares que vem sendo lançadas a cada dia no mercado brasileiro (MOREIRA; BENTO 2018). E é no desenvolvimento da floricultura tropical que o país mostra suas mais promissoras possibilidades ecológicas, produtivas e comerciais (TERAO; CARVALHO; BARROSO, 2005).

Em Minas Gerais o mercado de produção e de comercialização de flores é promissor, tanto de clima temperado quanto de clima tropical, devido à sua diversidade climática. A produção está distribuída em todas as regiões do estado, porém, para as flores tropicais, duas se destacam, a região Norte e a Zona da Mata (LUZ et al., 2005). As principais espécies tropicais cultivadas são: helicônias, alpínias, abacaxis ornamentais, estrelícias, bastões-do-imperador e gengibres ornamentais, entre outras.

A Strelitzia augusta Thumb., também conhecida como ave-do-paraíso-branca, pertence à ordem Zingiberales, anteriormente inclusa na família Musaceae, hoje pertence à família Strelitziaceae. É uma árvore semi-lenhosa, ereta, forma touceiras, com quatro a sete metros de altura, de folhagem decorativa, grandes, coriáceas e recurvadas. Tem origem na África do Sul e suas inflorescências são grandes, com espatas em forma de barco e flores brancas que se abrem sucessivamente (LORENZI; MELO FILHO, 2001; LAMAS, 2002).

Vários fatores estão envolvidos na qualidade dos produtos da floricultura, destacando-se entre eles, a adubação e a nutrição das plantas (FURLANI; CASTRO, 2001). Diante do exposto, o objetivo desse trabalho foi avaliar o teor e acúmulo nutricionais do rizoma e raiz de plantas de Strelitzia augusta, em solução nutritiva, sob deficiência de macronutrientes.

\section{MATERIAL E MÉTODO}

O experimento foi realizado durante os meses de setembro a março, em casa de vegetação do Departamento Ciência do Solo, na Universidade Federal de Lavras (Lavras, MG). As coordenadas geográficas são $21^{\circ} 14^{\prime} 30^{\prime}$ de latitude Sul e 4500'10” de longitude Oeste, altitude de 918 m (BRASIL, 1992). 
As plantas de Strelitzia augusta, utilizadas no experimento, foram propagadas via sementes e germinadas em bandeja de poliestireno expandido com 72 células individualizadas, com vermiculita. Trinta dias após a germinação, as mudas foram transferidas para a solução nutritiva completa de Hoagland; Arnon (1950), com 10\% da sua força iônica (período de adaptação), as quais permaneceram sob aeração constante da solução. A força iônica da solução nutritiva foi aumentada gradativamente durante o período experimental até atingir $100 \%$.

Após o período de adaptação, as plantas foram transplantadas para vasos com capacidade para 5 litros e aplicaram-se os tratamentos sob a técnica do elemento faltante. Utilizou-se o delineamento experimental inteiramente casualizado com três repetições e sete tratamentos: Solução Hoagland e Arnon (1950) completa (controle), solução completa menos N (-N), solução completa menos P (-P), solução completa menos K (-K), solução completa menos Ca (-Ca), solução completa menos $\mathrm{Mg}(-\mathrm{Mg})$ e solução completa menos S (-S). Cada parcela experimental foi constituída por uma planta por vaso.

Após os 180 dias de experimentação, as plantas foram colhidas, sendo lavadas as partes aéreas de cada planta em água corrente e em seguida em água destilada, sendo levadas para estufa de circulação forçada de ar, à temperatura de $65^{\circ}-70^{\circ} \mathrm{C}$, até que apresentasse peso constante. Posteriormente, o material vegetal foi pesado em balança de precisão para a determinação da massa de matéria seca.

Após a secagem, procedeu-se também à moagem para análise química, determinando-se os teores nutricionais da parte aérea seguindo os métodos descritos por Malavolta, Vitti e Oliveira (1997).

Os dados obtidos foram submetidos à análise de variância e as médias avaliadas pelo teste Scott; Knott, a 5\% de probabilidade. As análises estatísticas foram realizadas com o auxílio do programa computacional Sisvar (FERREIRA, 2010).

\section{RESULTADO E DISCUSSÃO}

Os teores de nitrogênio $(\mathrm{N})$, fósforo $(\mathrm{P})$, potássio $(\mathrm{K})$, cálcio $(\mathrm{Ca})$, magnésio $(\mathrm{Mg})$, enxofre $(\mathrm{S})$, boro $(\mathrm{B})$, cobre $(\mathrm{Cu})$, ferro $(\mathrm{Fe})$, manganês $(\mathrm{Mn})$ e zinco $(\mathrm{Zn})$ do rizoma e raiz de Strelitzia augusta, tiveram diferenças significativas em função dos tratamentos estudados e encontram-se na Tabela 1.

Os maiores teores de $\mathrm{N}$ do rizoma foram observados nas plantas dos tratamentos sob omissão de $\mathrm{K}$ e Ca com valores de 64,17 e 50,04 g. $\mathrm{kg}^{-1}$, devido, provavelmente, ao efeito de concentração desse nutriente e ausência do mecanismo de inibição competitiva existente entre $\mathrm{N}$ 
x K e N e Ca (MALAVOLTA; VITTI; OLIVEIRA, 1997). O menor teor desse nutriente foi observado nas plantas do tratamento sob omissão de $\mathrm{N}$, com redução de $82,15 \%$, em comparação ao tratamento completo. Resultados semelhantes foram observados por Frazão (2008) em plantas de bastão-do-imperador Etlingera elatior) e por Pinho (2007) em plantas de bananeira ornamental (Musa velutina).

Os maiores teores de $\mathrm{N}$ na raiz foram encontrados nas plantas dos tratamentos sob omissão de K, com valor 52,56\% maior, em comparação ao tratamento completo. Esse fato pode ser explicado pelo efeito de concentração, já que nesse tratamento as plantas tiveram baixa produção de matéria seca. Os menores teores de $\mathrm{N}$ foram observados em plantas sob omissão desse nutriente, com redução de $73,63 \%$, quando comparadas ao tratamento completo. Esses resultados corroboram com os encontrados por Naiff (2007), estudando omissão de macronutrientes em plantas de Alpinia purpurata.

Os sintomas da carência de $\mathrm{N}$ são primeiramente clorose generalizada das folhas mais velhas pela sua proteólise, resultando no colapso dos cloroplastos, ocorrendo declínio dos teores de clorofila. E os aminoácidos resultantes da proteólise são mobilizados para as partes mais novas, visto que o $\mathrm{N}$ é um nutriente de alta mobilidade no tecido vegetal. Com o agravamento da deficiência, toda a planta se torna clorótica pelo baixo teor de clorofila (COELHO et al., 2012).

Apenas as plantas cultivadas em solução deficiente em $\mathrm{P}$ apresentaram queda no teor desse elemento, com redução de $97,21 \%$, quando comparado ao tratamento completo. Coelho et $a l .$, (2012) trabalhando com sintomas visuais de deficiência de macronutrientes e boro em plantas de gengibre ornamental, observaram que após 56 dias da instalação do experimento, as plantas com carência de P começaram a manifestar os sintomas de deficiência. Os primeiros sintomas verificados nas plantas sob deficiência desse nutriente ocorreram nas folhas mais velhas devido à alta mobilidade de $\mathrm{P}$ nos tecidos vegetais das plantas sob deficiência de $\mathrm{P}$.

Assim como no rizoma, na raiz, houve queda significativa do teor de $\mathrm{P}$, somente nas plantas cultivadas sob omissão desse elemento, com redução de 93,26\% em comparação ao tratamento completo. As plantas com omissões de $\mathrm{K}, \mathrm{Ca}$ e $\mathrm{Mg}$ apresentaram altos teores desse nutriente, indicando efeito de concentração do mesmo. Além disso, Bergmann (1992) relata que a deficiência de $\mathrm{P}$ acarreta manchas necróticas marrom-escuras nas folhas velhas, lesões necróticas nas margens das folhas e morte com queda de folhas mais velhas. Souza et al. (2015) observaram que o maior teor de $\mathrm{P}$ nas raízes foi constatado na condição de omissão de $\mathrm{N}$.

Com exceção do tratamento $-\mathrm{K}$, não houve diferença significativa entre os tratamentos estudados para o teor de K. Entretanto, os maiores valores foram observados nas plantas com omissões de $\mathrm{N}$, Ca e $\mathrm{Mg}$, refletindo o efeito de concentração desse nutriente e ausência do 
mecanismo de inibição competitiva existente entre $\mathrm{K}$ x $\mathrm{N}, \mathrm{K}$ x $\mathrm{Ca}$ e $\mathrm{K}$ x $\mathrm{Mg}$ (BERGMANN, 1992).

Em relação ao teor de $\mathrm{K}$ da raiz, os maiores valores foram verificados nas plantas com omissões de $\mathrm{Ca}$ e $\mathrm{Mg}$, o que pode ser explicado pela ausência do mecanismo de inibição competitiva entre $\mathrm{K}$ x Ca e $\mathrm{K}$ x Mg (MALAVOLTA, 2006). O menor teor de $\mathrm{K}$ foi encontrado quando se omitiu esse nutriente, com redução de $92,48 \%$, quando comparado ao tratamento completo. Resultados semelhantes foram observados por Frazão (2008) em plantas de bastão-doimperador e por Almeida (2007) em plantas de copo-de-leite. Além disso, Coelho et al. (2012) trabalhando com gengibre ornamental revelou que as raízes das plantas sob omissão de K eram menos desenvolvidas em comparação ao tratamento completo. 
TABELA 1: Produção de matéria seca (MS) e teor (T) de nutrientes do rizoma e raiz de plantas de Strelitzia augusta sob omissão de macronutrientes. UFLA, Lavras, MG.

\begin{tabular}{|c|c|c|c|c|c|c|c|c|c|c|c|c|}
\hline \multirow{3}{*}{ Tratamento } & \multirow{3}{*}{$\begin{array}{c}\text { MS } \\
(\mathrm{g})\end{array}$} & \multicolumn{11}{|c|}{ Teores Nutricionais no rizoma } \\
\hline & & $\mathrm{N}$ & $\mathrm{P}$ & $\mathrm{K}$ & $\mathrm{Ca}$ & $\mathrm{Mg}$ & $S$ & $\mathrm{~B}$ & $\mathrm{Cu}$ & $\mathrm{Fe}$ & $\mathrm{Mn}$ & $\mathrm{Zn}$ \\
\hline & & \multicolumn{6}{|c|}{$\begin{array}{l}---------------------g . k g \\
--\end{array}$} & \multicolumn{5}{|c|}{ 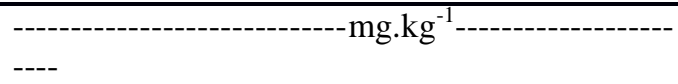 } \\
\hline Completo & 8,5 & $36,59 \mathrm{~d}$ & $8,61 \mathrm{~A}$ & $28,00 \mathrm{a}$ & $2,50 \mathrm{~b}$ & $3,55 b$ & $3,30 \mathrm{a}$ & $144,96 a$ & $4,04 \mathrm{a}$ & $236,49 a$ & $81,33 \mathrm{e}$ & $76,78 \mathrm{a}$ \\
\hline$-\mathbf{N}$ & 1,91 & $6,53 c$ & 7,17A & $25,67 \mathrm{a}$ & $2,41 b$ & $4,74 \mathrm{a}$ & $2,78 b$ & $112,25 b$ & $0,81 \mathrm{c}$ & $265,94 a$ & $746,77 \mathrm{a}$ & $33,20 \mathrm{c}$ \\
\hline$-\mathbf{P}$ & 10,02 & $32,43 c$ & $0,24 b$ & $25,33 \mathrm{a}$ & $1,69 \mathrm{c}$ & $3,83 b$ & $2,11 \mathrm{c}$ & $92,52 b$ & $1,48 \mathrm{c}$ & $277,54 a$ & $478,87 b$ & $64,17 b$ \\
\hline$-\mathbf{K}$ & 5,28 & $64,17 \mathrm{a}$ & $10,31 \mathrm{~A}$ & $1,67 b$ & $3,80 \mathrm{a}$ & $3,24 b$ & $3,85 \mathrm{a}$ & $136,67 \mathrm{a}$ & $3,24 \mathrm{a}$ & $263,26 a$ & $172,16 \mathrm{c}$ & $71,03 b$ \\
\hline$-\mathbf{C a}$ & 4,94 & $50,04 b$ & $10,42 \mathrm{~A}$ & $27,00 \mathrm{a}$ & $0,20 \mathrm{~d}$ & $3,00 \mathrm{~b}$ & $3,51 \mathrm{a}$ & $92,37 b$ & $4,55 \mathrm{a}$ & $126,72 b$ & $127,77 d$ & $81,82 \mathrm{a}$ \\
\hline$-\mathrm{Mg}$ & 5,53 & $40,77 \mathrm{c}$ & $10,62 \mathrm{~A}$ & $27,33 \mathrm{a}$ & $2,82 b$ & $0,33 \mathrm{c}$ & $2,32 \mathrm{c}$ & $123,32 \mathrm{a}$ & $2,41 b$ & $290,03 a$ & $38,12 \mathrm{e}$ & $84,06 a$ \\
\hline$-S$ & 7,24 & $43,68 \mathrm{c}$ & $9,36 \mathrm{~A}$ & $23,33 a$ & $1,92 \mathrm{c}$ & $4,62 \mathrm{a}$ & $2,95 b$ & $113,76 b$ & $3,73 \mathrm{a}$ & $240,95 a$ & $109,80 d$ & $87,71 \mathrm{a}$ \\
\hline \multirow[t]{2}{*}{$\mathrm{CV}(\%)$} & & 12,97 & 20,05 & 11,2 & 13,3 & 17,57 & 11,32 & 13,68 & 15,2 & 23,8 & 11,26 & 11 \\
\hline & \multicolumn{12}{|c|}{ Teores Nutricionais na raiz } \\
\hline Completo & 6,3 & $33,23 b$ & $11,27 \mathrm{~A}$ & $26,60 \mathrm{a}$ & $2,23 b$ & $2,44 \mathrm{c}$ & $4,25 \mathrm{a}$ & $201,94 a$ & $8,81 \mathrm{c}$ & $4210,38 c$ & $130,65 c$ & $81,75 c$ \\
\hline$-\mathbf{N}$ & 6 & $9,24 c$ & $8,91 b$ & $23,70 b$ & $2,08 \mathrm{~b}$ & $3,23 a$ & $3,22 b$ & $146,35 b$ & $3,42 \mathrm{~d}$ & $1091,42 d$ & $364,99 b$ & $41,33 d$ \\
\hline$-\mathbf{P}$ & 7,37 & $32,99 b$ & $0,76 \mathrm{c}$ & $23,20 b$ & $1,75 b$ & $2,90 \mathrm{~b}$ & $5,57 \mathrm{a}$ & $106,44 c$ & $23,84 \mathrm{a}$ & $5355,34 b$ & $527,45 \mathrm{a}$ & $274,59 a$ \\
\hline$-K$ & 3,35 & $50,73 a$ & $12,24 \mathrm{~A}$ & $2,00 \mathrm{c}$ & $2,99 a$ & $2,79 b$ & $5,07 \mathrm{a}$ & $141,01 b$ & $9,65 \mathrm{c}$ & $6597,68 \mathrm{a}$ & $75,19 \mathrm{c}$ & $64,08 \mathrm{~d}$ \\
\hline$-\mathrm{Ca}$ & 4,11 & $39,11 b$ & $11,87 \mathrm{~A}$ & $27,60 \mathrm{a}$ & $0,19 \mathrm{c}$ & $1,92 \mathrm{~d}$ & $4,91 \mathrm{a}$ & $101,71 \mathrm{c}$ & $10,42 \mathrm{c}$ & $3259,52 \mathrm{c}$ & $118,27 \mathrm{c}$ & $83,51 \mathrm{c}$ \\
\hline$-\mathrm{Mg}$ & 3,87 & $30,52 b$ & $11,60 \mathrm{~A}$ & $23,63 b$ & $2,85 \mathrm{a}$ & $0,65 \mathrm{e}$ & $3,30 \mathrm{~b}$ & $156,89 b$ & $8,07 \mathrm{c}$ & $4358,52 \mathrm{c}$ & $151,99 \mathrm{c}$ & $87,70 \mathrm{c}$ \\
\hline$-S$ & 6,37 & $33,59 \mathrm{~b}$ & $11,97 \mathrm{~A}$ & $22,80 \mathrm{~b}$ & $2,08 \mathrm{~b}$ & $2,31 \mathrm{c}$ & $3,29 b$ & $104,77 \mathrm{c}$ & $13,41 \mathrm{~b}$ & $3974,78 \mathrm{c}$ & $108,28 \mathrm{c}$ & $120,62 b$ \\
\hline $\mathrm{CV}(\%)$ & & 12,84 & 9,79 & 7,26 & 24,15 & 8,26 & 14,9 & 12,78 & 8,72 & 15,24 & 25,79 & 14,86 \\
\hline
\end{tabular}

Médias seguidas de mesma letra na coluna não diferem entre si, pelo teste Scott \& Knott a $5 \%$ de probabilidade.

Coelho et al. (2017) trabalhando com deficiências nutricionais, e composição mineral de Zingiber spectabile, observou que a omissão de $\mathrm{K}$ da solução de cultivo acarretou em aumento nos teores de Mn e Zn na parte aérea e rizoma dessas plantas. Entretanto não observou diferença para as raízes.

Os maiores teores de Ca no rizoma foram observados nas plantas cultivadas sob omissão de K, o que pode ser justificado pela ausência do mecanismo de inibição competitiva entre esses cátions na omissão de um deles (MALAVOLTA, 2006). Os menores teores de Ca foram observados nas plantas do tratamento em que se omitiu esse elemento, com redução de $92 \%$, em comparação ao tratamento completo.

Os maiores teores de $\mathrm{Ca}$ da raiz foram observados nas plantas dos tratamentos $-\mathrm{K} \mathrm{e}-\mathrm{Mg}$, devido, possivelmente, a ausência do mecanismo de inibição competitiva entre esses cátions (MALAVOLTA, 2006). Já os menores teores foram observados quando se omitiu esse nutriente, com redução de $91,48 \%$, em comparação ao tratamento completo. Resultado esse, refletido no acúmulo desse nutriente.

Souza et al. (2015) estudando amoreira-preta observou que o maior valor de Ca encontrados na parte aérea, foi verificado nas plantas dos tratamentos sob omissão de $\mathrm{N}$ (efeito de 
concentração de $\mathrm{Ca}$, devido à menor produção de biomassa, limitada pelo fornecimento de $\mathrm{N}$ ), enquanto os menores valores foram observados em plantas com solução nutritiva sem Ca. Quanto aos teores de $\mathrm{Ca}$ nas raízes, os menores valores foram encontrados em plantas cultivadas em solução nutritiva com ausência de $\mathrm{N}, \mathrm{P}, \mathrm{K}, \mathrm{Ca}, \mathrm{Mg}, \mathrm{B}$ e Fe, quando comparadas com o tratamento controle

Coelho et al. (2012) observaram que o sintoma típico da ausência de Ca é a necrose das regiões meristemáticas jovens, como ápices das raízes e folhas mais novas, possivelmente pela dissolução da parede celular. Nas folhas mais jovens, o primeiro sintoma é a clorose em suas extremidades e, nos estágios mais avançados, ocorre necrose. As plantas utilizam Ca na síntese da parede celular, particularmente na lamela média, que separa as células em divisão, além do requerido para funcionamento normal das membranas vegetais. Por esse motivo, os sintomas de carência do Ca ocorrem nas partes mais jovens, tanto na parte aérea como no sistema radicular.

Para o teor de $\mathrm{Mg}$, os maiores valores foram observados nas plantas cultivadas sob omissão de $\mathrm{N}$. Esse fato deve-se à ausência do mecanismo de interação competitiva entre $\mathrm{Mg} \times \mathrm{N}$ (BERGMANN, 1992). Quando o Mg foi omitido da solução nutritiva, foi verificado o menor teor desse nutriente, com redução de 73,36\% em comparação ao tratamento completo. Resultados semelhantes foram observados por Frazão (2008), em plantas de Etlingera elatior (bastão-doimperador).

$\mathrm{Na}$ análise do $\mathrm{Mg}$ no rizoma, os maiores teores foram verificados nas plantas dos tratamentos $-\mathrm{N}$ e $-\mathrm{S}$, resultado do efeito de concentração desse nutriente nas plantas sob deficiência de $\mathrm{N}$, no caso do resultado encontrado no tratamento sob omissão de $\mathrm{S}$ para essa característica, não há relatos na literatura sobre antagonismo entre o Mg e o S. Já os menores teores foram verificados nas plantas sob omissão de $\mathrm{Mg}$, com redução de 90,70\%, quando comparados ao tratamento completo.

Os sintomas de carência de Mg são primeiramente visualizados nas folhas mais velhas pela mobilidade desse nutriente no tecido vegetal, caracterizados por clorose entre as nervuras. Tal fenômeno pode ser explicado pela permanência da clorofila nas nervuras por períodos maiores que a clorofila do limbo foliar (entre as nervuras). Sob deficiência severa, toda a planta se torna clorótica (COELHO et al., 2012).

Em relação aos teores de $\mathrm{S}$ no rizoma, os maiores foram observados nas plantas sob omissões de $\mathrm{K}$ e $\mathrm{Ca}$, não diferindo estatisticamente do tratamento completo. Esses dados corroboram com os encontrados por Naiff (2007), estudando plantas de Alpinia purpurata. 
Souza et al., (2015) verificou que no sistema radicular, o maior valor de S foi observado em plantas submetidas a solução nutritiva com ausência de N, pois há uma relação positiva entre os elementos $\mathrm{N}$ e $\mathrm{S}$.

Mesmo sendo menor o teor de enxofre em relação à testemunha, alto teor de $\mathrm{S}$ verificado nas plantas do tratamento em que se omitiu esse nutriente pode ser explicado pela capacidade das folhas conseguirem absorver o gás $\mathrm{SO}_{2}$ do ar (MALAVOLTA, 2006). Provavelmente houve uma contaminação do ar por S, já que o local de condução do experimento fica próximo a laboratórios que trabalham com esse elemento, o que proporcionou uma absorção foliar do mesmo.

Houve diminuição nos teores de $\mathrm{S}$ na raiz das plantas cultivadas sob a omissão desse elemento, bem como na ausência de $\mathrm{N}$ e $\mathrm{Mg}$. O menor teor de $\mathrm{Mg}$ foi observado quando se omitiu esse nutriente da solução de cultivo, com redução de 84,09\%, em comparação ao tratamento completo.

Os tratamentos sob omissão de $\mathrm{K}$ e $\mathrm{Mg}$ não diferiram da testemunha, apresentando os maiores teores de $\mathrm{B}$ no rizoma. O alto teor desse nutriente nas plantas sob omissão de $\mathrm{K}$, deve-se a redução do efeito antagônico entre B e K (BERGMANN, 1992), favorecendo a absorção de B. Resultados semelhantes foram encontrados por Frazão (2008), estudando plantas de bastão-doimperador (Etlingera elatior).

Coelho et al., (2017) analisando-se os teores de B no rizoma de Zingiber spectabile, observaram que a omissão de $\mathrm{K}$ acarretou aumento dos teores desse micronutriente no tecido vegetal.

Plantas cultivadas sob omissão de $\mathrm{Ca}, \mathrm{Mg}$ e S apresentaram teores mais elevados de Zn no rizoma, não diferindo estatisticamente daquelas cultivadas em condições normais. Para a omissão de $\mathrm{Ca}$, esse resultado pode ser explicado pela ausência do mecanismo de inibição competitiva entre Zn x Ca (MALAVOLTA; VITTI; OLIVEIRA, 1997).

A carência de $\mathrm{Ca}$, normalmente, retarda o crescimento e causa a morte dos ponteiros. $\mathrm{O}$ cálcio é absorvido pelas raízes como $\mathrm{Ca}^{+2}$ e o seu movimento ascendente se dá por meio de reações de troca em vasos condutores, mais do que por fluxo de massa. Depois de localizado nas folhas, o Ca se torna imóvel. A falta de cálcio afeta, particularmente, os pontos de crescimento da raiz, sendo que aparecem núcleos poliploides, células binucleadas, núcleos constritos e divisões amitóticas, bem como cessa o desenvolvimento e há escurecimento e morte (SOUZA et al., 2015).

Todas as omissões resultaram em diminuição do teor de B em raízes de Strelitzia augusta e esse resultado refletiu no acúmulo desse nutriente nessa espécie. Os maiores teores e acúmulos de $\mathrm{Zn}$ foram encontrados nas plantas cultivadas sob omissão de $\mathrm{P}$, com valores bem mais 
elevados dos observados nas plantas do tratamento completo. Isso se deve, à ausência do mecanismo de inibição não competitiva, existente entre esses nutrientes (MALAVOLTA; VITTI; OLIVIEIRA, 1997). Esses resultados corroboram com os encontrados por Frazão (2008), estudando plantas de Etlingera elatior (bastão-do-imperador).

Para os teores de $\mathrm{Cu}$ do rizoma, os maiores valores foram encontrados nas plantas dos tratamentos -Ca, completo, $-\mathrm{S}$ e -K. Esse fato pode ser explicado pelo efeito de concentração do $\mathrm{Cu}$ e ausência do mecanismo de inibição competitiva entre $\mathrm{Cu} \times \mathrm{Ca}$ e $\mathrm{Cu} \times \mathrm{K}$ (MALAVOLTA, 2006). Já os menores teores de $\mathrm{Cu}$ foram observados nas plantas dos tratamentos $-\mathrm{P}$ e $-\mathrm{N}$, devido, provavelmente no caso da omissão de $\mathrm{P}$ efeito de diluição. Todos os tratamentos apresentaram queda nos acúmulos de $\mathrm{Cu}$ no rizoma das plantas em relação à testemunha.

Os maiores teores de $\mathrm{Cu}$ da raiz foram encontrados nas plantas sob omissão de P. A literatura cita que esses elementos apresentam certo antagonismo, haja vista que no excesso de um, a planta apresenta deficiência do outro. Já o menor teor foi observado nas plantas sob omissão de N. Houve aumento no teor de Fe das raízes quando se omitiu $\mathrm{K}$ da solução de cultivo, reflexo da baixa produção de matéria seca de raízes dessas plantas e pela ausência do mecanismo de inibição competitiva Fe x K (MALAVOLTA; VITTI; OLIVEIRA, 1997).

As raízes das plantas sob carência de $\mathrm{Cu}$ apresentaram diminuição no crescimento, conferindo um aspecto menos denso ao sistema radicular, além de raízes com coloração mais escura. $\mathrm{O} \mathrm{Cu}$ atua na síntese de proteínas, diminuindo em plantas deficientes, o que pode ser devido ao seu papel como co-fator para a síntese de enzimas do DNA e RNA (PINHO et al., 2012).

Dentre os tratamentos estudados, somente na omissão de Ca houve queda nos teores de $\mathrm{Fe}$ nos rizomas das plantas. Na omissão de $\mathrm{P}$ houve o maior acúmulo de $\mathrm{Fe}$ devido à grande produção de matéria seca do rizoma e ao alto teor do elemento nessa parte da planta.

Souza et al. (2015) estudando sintomas de deficiência de macronutrientes na amoreirapreta observaram que com a omissão de $\mathrm{Fe}$, ocorreu clorose internerval nas folhas mais novas, formando um reticulado fino. Em seguida, identificou-se necrose foliar, que evoluiu das margens para o centro, e morte do meristema apical.

Para o teor de Mn do rizoma, os maiores valores foram observados nas plantas com omissão de $\mathrm{N}$, refletindo efeito de concentração desse nutriente devido à baixa produção de matéria seca nessas plantas. Os maiores teores de $\mathrm{Mn}$ da raiz foram encontrados nas plantas cultivadas sob omissões de P, com valores muito superiores ao completo. Pinho et al., (2012) estudando o Antúrio observou que as plantas sob omissão desse nutriente apresentaram menor porte, quando comparadas às plantas do tratamento completo. 
Os acúmulos de nitrogênio $(\mathrm{N})$, fósforo $(\mathrm{P})$, potássio $(\mathrm{K})$, cálcio $(\mathrm{Ca})$, magnésio $(\mathrm{Mg})$, enxofre $(\mathrm{S})$, boro $(\mathrm{B})$, cobre $(\mathrm{Cu})$, ferro $(\mathrm{Fe})$, manganês $(\mathrm{Mn})$ e zinco $(\mathrm{Zn})$ do rizoma de Strelitzia augusta, apresentaram diferenças significativas em função dos tratamentos estudados e encontram-se na Tabela 2.

Os maiores acúmulos de $\mathrm{N}$ do rizoma foram encontrados nos tratamentos $-\mathrm{K}$, -P, $-\mathrm{S}$ e completo, provavelmente devido ao alto teor verificado no primeiro e à maior produção de matéria seca nos demais, enquanto o menor acúmulo foi encontrado nas plantas do tratamento em que se omitiu o $\mathrm{N}$.

Os maiores acúmulos de $\mathrm{N}$ da raiz foram encontrados nas plantas dos tratamentos $-\mathrm{S}$, completo e -P, possivelmente pela maior produção de matéria seca. Já os menores valores foram encontrados nas plantas sob omissão de $\mathrm{N}$ e $\mathrm{Mg}$, com reduções de 73,63 42,39\%, respectivamente, quando comparadas ao tratamento completo.

Em relação ao acúmulo de $\mathrm{P}$ do rizoma, somente houve diferença estatística para as plantas dos tratamentos sob omissões de $\mathrm{P}$ e N. Para a omissão de $\mathrm{P}$, esse fato pode ser explicado pelo baixo teor encontrado, enquanto para a omissão de $\mathrm{N}$, pela baixa produção de matéria seca do rizoma.

Os maiores acúmulos de $\mathrm{P}$ da raiz, foram observados nas plantas dos tratamentos completo e $-\mathrm{S}$, devido provavelmente a maiores produções de matéria seca de raiz. Os menores valores foram encontrados nas plantas sob omissão de P, com redução de 93,23\%, em comparação ao tratamento completo.

Souza et al., (2015) observaram que para o acúmulo de fósforo no sistema radicular, os menores valores foram encontrados em plantas dos tratamentos com omissões de $\mathrm{Fe}, \mathrm{K}, \mathrm{B}, \mathrm{Ca}$ e $\mathrm{P}$, quando comparados com o tratamento controle 
TABELA 2: Produção de matéria seca (MS) e acúmulo (AC) de nutrientes pelo rizoma e raiz de plantas de Strelitzia augusta sob omissão de macronutrientes. UFLA, Lavras, MG.

\begin{tabular}{|c|c|c|c|c|c|c|c|c|c|c|c|c|}
\hline \multirow{3}{*}{ Tratamento } & \multicolumn{12}{|c|}{ Acúmulo Nutricionais no rizoma } \\
\hline & \multirow{2}{*}{$\begin{array}{c}\text { MS } \\
(\mathrm{g})\end{array}$} & $\mathrm{N}$ & $\mathrm{P}$ & $\mathrm{K}$ & $\mathrm{Ca}$ & $\mathrm{Mg}$ & $\mathrm{S}$ & $\mathrm{B}$ & $\mathrm{Cu}$ & $\mathrm{Fe}$ & $\mathrm{Mn}$ & $\mathrm{Zn}$ \\
\hline & & ------------ & ----------- & $\mathrm{kg}^{-1}--\cdot-\cdot-\cdot-$ & -----------. & & & \multicolumn{5}{|c|}{ - } \\
\hline Completo & & $312,10 \mathrm{a}$ & $73,30 \mathrm{a}$ & $235,53 a$ & $21,14 \mathrm{a}$ & $30,62 \mathrm{a}$ & $27,80 \mathrm{~A}$ & $1214,06 \mathrm{a}$ & $34,53 \mathrm{a}$ & $2014,38 b$ & $697,78 c$ & $653,94 \mathrm{a}$ \\
\hline$-\mathbf{N}$ & & $12,34 \mathrm{c}$ & $13,56 b$ & $48,12 \mathrm{c}$ & $4,60 \mathrm{c}$ & $8,77 \mathrm{c}$ & $5,36 \mathrm{~d}$ & $215,14 d$ & $1,54 \mathrm{~d}$ & $516,04 c$ & $1434,89 b$ & $62,03 c$ \\
\hline$-\mathbf{P}$ & & $325,24 a$ & $2,37 \mathrm{~b}$ & $257,48 \mathrm{a}$ & $16,96 \mathrm{~b}$ & $38,50 \mathrm{a}$ & $21,04 b$ & $925,98 b$ & $14,78 \mathrm{c}$ & $2771,68 \mathrm{a}$ & $4804,04 a$ & $639,88 \mathrm{a}$ \\
\hline$-K$ & & $338,71 \mathrm{a}$ & $54,47 \mathrm{a}$ & $10,56 c$ & $20,14 a$ & $17,10 \mathrm{~b}$ & $20,33 b$ & $723,70 \mathrm{~b}$ & $17,18 \mathrm{c}$ & $1390,36 b$ & $908,17 \mathrm{c}$ & $375,23 b$ \\
\hline$-\mathrm{Ca}$ & & $244,88 b$ & $51,46 a$ & $135,01 \mathrm{~b}$ & $0,98 \mathrm{c}$ & $14,79 b$ & $17,27 b$ & $454,96 \mathrm{c}$ & $22,60 \mathrm{~b}$ & $669,07 \mathrm{c}$ & $627,02 \mathrm{c}$ & $407,17 b$ \\
\hline -Mg & & $226,94 b$ & $58,75 \mathrm{a}$ & $152,12 b$ & $15,49 \mathrm{~b}$ & $1,82 \mathrm{c}$ & $12,90 \mathrm{c}$ & $688,28 b$ & $13,14 \mathrm{c}$ & $1610,57 b$ & $212,19 d$ & $464,23 b$ \\
\hline$-S$ & & $315,80^{\mathrm{a}}$ & $67,84 a$ & $169,25 \mathrm{~b}$ & $13,81 b$ & $33,38 \mathrm{a}$ & $21,39 b$ & $822,90 \mathrm{~b}$ & $27,00 \mathrm{~b}$ & $1751,60 \mathrm{~b}$ & $795,48 c$ & $633,56 a$ \\
\hline \multirow[t]{2}{*}{$\mathrm{CV}(\%)$} & & 16,34 & 25,42 & 16,42 & 15,51 & 25,73 & 11,41 & 14,78 & 19,38 & 28,38 & 19,08 & 18 \\
\hline & & \multicolumn{11}{|c|}{ Acúmulo Nutricionais na raiz } \\
\hline Completo & & $210,40^{\mathrm{a}}$ & $71,18 \mathrm{a}$ & $166,60 \mathrm{a}$ & $14,23 \mathrm{a}$ & $15,40 \mathrm{a}$ & $27,00 \mathrm{a}$ & $1247,75 \mathrm{a}$ & $55,10 \mathrm{c}$ & $26538,85 b$ & $822,30 \mathrm{c}$ & $515,09 \mathrm{c}$ \\
\hline$-\mathbf{N}$ & & $55,49 \mathrm{c}$ & $52,57 \mathrm{~b}$ & $143,16 a$ & $12,60 \mathrm{a}$ & $18,44 \mathrm{a}$ & $18,67 b$ & $886,13 b$ & $21,11 d$ & $6557,73 d$ & $2048,92 b$ & $262,56 \mathrm{~d}$ \\
\hline$-\mathbf{P}$ & & $209,48^{a}$ & $4,82 \mathrm{C}$ & $147,13 \mathrm{a}$ & $11,11 \mathrm{a}$ & $18,35 \mathrm{a}$ & $32,20 \mathrm{~A}$ & $678,12 c$ & $151,16 \mathrm{a}$ & $33931,76 a$ & $3355,66 a$ & $1737,71 \mathrm{a}$ \\
\hline$-K$ & & $169,96^{\mathrm{a}}$ & $41,14 b$ & $6,61 \mathrm{c}$ & $9,96 a$ & $9,36 b$ & $15,48 b$ & $474,50 \mathrm{c}$ & $32,19 \mathrm{~d}$ & $22098,01 b$ & $242,47 \mathrm{c}$ & $214,94 d$ \\
\hline$-\mathbf{C a}$ & & $161,65^{a}$ & $48,86 b$ & $113,50 \mathrm{~b}$ & $0,54 b$ & $8,06 \mathrm{~b}$ & $20,10 b$ & $417,10 \mathrm{c}$ & $42,80 \mathrm{~d}$ & $13391,19 \mathrm{c}$ & $486,99 \mathrm{c}$ & $343,39 d$ \\
\hline -Mg & & $121,21 b$ & $44,19 B$ & $91,63 b$ & $11,44 a$ & $2,45 c$ & $12,86 b$ & $596,37 \mathrm{c}$ & $31,66 \mathrm{~d}$ & $16529,18 \mathrm{c}$ & $588,81 \mathrm{c}$ & $341,71 \mathrm{~d}$ \\
\hline$-S$ & & $210,61^{a}$ & $74,94 \mathrm{a}$ & $142,55 \mathrm{a}$ & $13,09 \mathrm{a}$ & $14,45 \mathrm{a}$ & $20,64 b$ & $656,76 \mathrm{c}$ & $83,84 b$ & $25071,17 b$ & $678,98 \mathrm{c}$ & $754,55 b$ \\
\hline $\mathrm{CV}(\%)$ & & 21,23 & 18,58 & 20,3 & 25,22 & 21,05 & 17,41 & 18,43 & 12,56 & 20,91 & 22,42 & 19,09 \\
\hline
\end{tabular}

Médias seguidas de mesma letra na coluna não diferem entre si, pelo teste Scott \& Knott a 5\% de probabilidade. 
Os maiores acúmulos de $\mathrm{K}$ do rizoma foram verificados nas plantas dos tratamentos -P, completo e -S, possivelmente devido à maior produção de matéria seca. Já os menores acúmulos desse nutriente foram encontrados nas omissões de K e N com reduções de 95,52 e 79,57\%, respectivamente, em comparação ao tratamento completo.

Os maiores acúmulos de $\mathrm{K}$ da raiz foram observados nas plantas dos tratamentos completo e -S, possivelmente pela maior produção de matéria seca. Já o menor acúmulo foi observado nas plantas sob omissão de K, com redução de 96,03\%, quando comparadas ao tratamento completo.

Os maiores acúmulos de $\mathrm{Ca}$ no rizoma foram encontrados nas plantas do tratamento completo e sob omissão de K, devido, provavelmente, à grande produção de matéria seca pelas plantas no primeiro e ao alto teor de no segundo tratamento citado. Os menores acúmulos foram observados nas plantas sob omissão de $\mathrm{Ca}$ e $\mathrm{N}$, pelo fato de apresentarem baixa produção de matéria seca e baixos teores do elemento no rizoma.

Os maiores acúmulos de $\mathrm{Mg}$ do rizoma foram observados nas plantas dos tratamentos completo, -P e -S, possivelmente pela maior produção de matéria seca aliada aos maiores teores do elemento no rizoma. Pelo menor teor de Mg no rizoma, o tratamento onde se omitiu esse elemento apresentou também o menor acúmulo, com redução de 94,05\%, em comparação ao tratamento completo.

As plantas cultivadas sob solução nutritiva completa apresentaram maiores acúmulos de $\mathrm{S}$ em relação àquelas cultivadas sob omissão nutricional, isso se deve ao fato de as mesmas apresentarem alto teor do elemento aliado à boa produção de matéria seca.

Em relação ao acúmulo de $\mathrm{Mg}$ da raiz, os maiores valores foram verificados nas plantas dos tratamentos $-\mathrm{N}$, -P e $-\mathrm{S}$, não diferindo do tratamento completo, devido, possivelmente, a maior produção de matéria seca pelas plantas nesses tratamentos.

Os maiores acúmulos de $\mathrm{S}$ nas raízes foram encontrados nas plantas cultivadas sob omissão de $\mathrm{P}$ e no tratamento completo, devido à maior produção de matéria seca aliada ao alto teor do elemento em sua constituição.

Todos os tratamentos resultaram em queda no acúmulo de $\mathrm{B}$ em rizomas quando comparados ao tratamento completo, reflexo dos altos teores aliados à grande produção de matéria seca nessa parte pelas plantas nessa condição.

Assim como o acúmulo de $\mathrm{B}$ do rizoma, os maiores acúmulos foram verificados nas plantas dos tratamentos completo, $-\mathrm{P}$ e $-\mathrm{S}$, devido provavelmente a maior produção de matéria seca.

Os maiores acúmulos de Mn no rizoma foram verificados nas plantas dos tratamentos sob omissões de $\mathrm{P}$, devido, provavelmente, à maior produção de matéria seca. Pinho et al. (2012) 
observaram que as plantas sob omissão de Mn apresentaram menor porte, quando comparadas às plantas do tratamento completo. Além disso, o autor relata que o Mn está ligado à síntese de clorofila, e a maior parte dele encontra-se nos cloroplastos, participando de processos de transporte eletrônico na fase luminosa da fotossíntese e sob omissão de Mn a estrutura dos cloroplastos é alterada

Em relação ao acúmulo de $\mathrm{Cu}$ da raiz, os maiores valores foram observados nas plantas do tratamento -P, devido, possivelmente, à maior produção de matéria seca. Pinho et al., (2012) observaram que as plantas com omissão de $\mathrm{Cu}$ apresentaram porte reduzido, e com o avanço da carência as folhas mais novas eram mal formadas com maior espessura e encarquilhadas.

Foram observados os maiores acúmulos de Fe na raiz em plantas sob omissão de $\mathrm{P}$, devido à maior produção de matéria seca. Entre as partes das plantas, a raiz foi o órgão que apresentou os maiores teores e acúmulos de Fe, indicando sua menor mobilidade dentro da planta. Souza et al. (2015) relata que o transporte de ferro se dá na corrente transpiratória e, no exsudado do xilema, o ferro aparece largamente como quelado de ácido cítrico. Na planta em desenvolvimento e na adulta, entretanto, não se dá, praticamente, a redistribuição do Fe e, como consequência, a lâmina foliar amarelece, enquanto as nervuras podem ficar verdes durante algum tempo, destacando-se como um reticulado muito fino. Em casos extremos, as folhas adquirem coloração esbranquiçada.

Os maiores acúmulos de $\mathrm{Mn}$ da raiz foram encontrados nas plantas cultivadas sob omissões de P, com valores muito superiores ao completo.

\section{CONCLUSÃO}

O balanço nutricional de qualquer vegetal é importante para seu crescimento saudável, visto que as deficiências de macronutrientes causam alterações nos teores e acúmulos do rizoma e raízes de plantas de Strelitzia augusta.

Os teores dos macronutrientes encontrados no rizoma de Strelitzia augusta no tratamento completo são $\left(\mathrm{g} \mathrm{kg}^{-1}\right)$ : N 36,59; P 8,61; K 28,0; Ca 2,50; $\mathrm{Mg} 3,55 ; \mathrm{S} \mathrm{3,30,} \mathrm{e} \mathrm{os} \mathrm{teores} \mathrm{dos}$ micronutrientes encontrados no rizoma de Strelitzia augusta no tratamento completo são (mg kg$\left.{ }^{1}\right)$ : B 144,56; Cu 4,64; Fe 236,49; Mn 81,33; Zn 76,78.

A ordem decrescente de acúmulo de macronutrientes no rizoma de Strelitzia augusta em solução nutritiva é $\mathrm{N}>\mathrm{K}>\mathrm{P}>\mathrm{Mg}>\mathrm{Ca}>\mathrm{S}$. A ordem decrescente de acúmulo de micronutrientes no rizoma de Strelitzia augusta em solução nutritiva é $\mathrm{Fe}>\mathrm{B}>\mathrm{Mn}>\mathrm{Zn}>\mathrm{Cu}$. 
Os teores dos macronutrientes encontrados nas raízes de Strelitzia augusta no tratamento completo são $\left(\mathrm{g} \mathrm{kg}^{-1}\right)$ : N 33,23; P 11,27; K 26,60; Ca 2,33; $\mathrm{Mg}$ 2,44; S 4,25, e os teores dos micronutrientes encontrados no rizoma de Strelitzia augusta no tratamento completo são (mg kg 1): B 201,94; Cu 8,81; Fe 4210,38; Mn 130,65; Zn 81,75.

A ordem decrescente de acúmulo de macronutrientes no rizoma de Strelitzia augusta em solução nutritiva é $\mathrm{N}>\mathrm{K}>\mathrm{P}>\mathrm{S}>\mathrm{Mg}>\mathrm{Ca}$. A ordem decrescente de acúmulo de micronutrientes nas raízes de Strelitzia augusta é a mesma apresentada no rizoma.

\section{REFERÊNCIAS}

ALMEIDA, E. F.A. Nutrição mineral em plantas de copo-de-leite: deficiência de nutrientes e adubação silicatada. 2007. 109p. Tese (Doutorado em Fitotecnia) - Universidade Federal de Lavras, Lavras-MG.

BERGMANN, W. Nutritional disorders of plants. New York: Gustav Fischer, 1992. 741p.

BRASIL. Ministério da Agricultura. Escritório de Meteorologia. Normais climatológicas: 19611990. Brasília: SNI/INME, 1992. 84 p.

COELHO, V. A. T. et al. Potássio e sódio na composição mineral e crescimento em plantas de Zingiber spectabile. Agrária - Revista Brasileira de Ciências Agrárias ISSN (on line) 19810997. v.12, n.1, p.35-40, 2017.

COELHO, V. A. T. et al. Caracterização de sintomas visuais de deficiências de macronutrientes e boro em plantas de gengibre ornamental. Revista Brasileira de Horticultura Ornamental. v. 18, n.1, p. 47-55, 2012.

FERREIRA, D. F. SISVAR software: versão 5.6. Lavras: DEX/UFLA, 2010. Software.

FRAZÃO, J. E. M. Diagnose da deficiência nutricional e crescimento do Bastão-doImperador Etlingera elatior (Jack) R. M. Smith com o uso da técnica do elemento faltante em solução nutritiva, 2008. 67p. Tese (Doutorado em solos e Nutrição de Plantas) Universidade Federal de Lavras, Lavras-MG.

FURLANI, A. M. C.; CASTRO, C. E. F. Plantas ornamentais e flores. In: FERREIRA, M.E. CRUZ, M. C. P.; RAIJ, B.; ABREU, C. A. Micronutrientes e elementos tóxicos na agricultura. Jaboticabal: CNPq/ FAPESP/ POTAFOS, 2001. p.533-552.

HOAGLAND, D.R.; ARNON, D.L. The water culture methods for growing plants without soil. Berkeley, California Agriculture Experiment Station, 1950. 32 p. (Bulletin, 347).

LAMAS, A. M. Floricultura tropical: técnicas de cultivo. Recife: SEBRAE/PE, 2002, 88p.

LORENZI, H.; MELO FILHO, L. E. As plantas tropicais de R. Burble Marx. São Paulo: Instituto Plantarum de Estudos da Flora, 2001. 488p. 
LUZ, P. B., et al. Cultivo de Flores Tropicais. In: INFORME AGROPECUÁRIO. EPAMIG. Floricultura. Belo Horizonte-MG, v. 26, n. 227, 2005.

MALAVOLTA, E. Manual de nutrição mineral de plantas. São Paulo: Agronômica Ceres, 2006. 638p.

MALAVOLTA, E.; VITTI, G. C.; OLIVEIRA, S. A. Avaliação do estado nutricional das Plantas: princípios e aplicações. Piracicaba: Potafos, 1997. 319p.

MOREIRA, M. L.; BENTO, C. S. Levantamento da produção de flores e plantas ornamentais no Caparaó Capixaba. SEAGRO: Anais de Semana Acadêmica do Curso de Agronomia do CCAE/UFES, v. 2, n.1, 2018 ISSN: 2594-4452

NAIFF, A. P. M. Crescimento, Composição Mineral e Sintomas Visuais de Deficiências de Macronutrientes em Plantas de Alpinia purpurata cv. Jungle King. 2007. 77p. Tese de Mestrado. Universidade Federal Rural da Amazônia, Belém-PA.

PINHO, P.J.; FRAZÃO, J.E.M.; SOUZA, G.A.; CARVALHO, J.G.; BASTOS, A.R.R.; OLIVEIRA, N.P. Sintomas visuais de deficiências simples e múltiplas de micronutrientes em antúrio. Revista Brasileira de Horticultura Ornamental, v.18, p.63-70, 2012.

SOUZA, F. B. M. et al. Sintomas visuais de deficiência de macronutrientes, boro e ferro e composição mineral de amoreira preta. e-ISSN 1983-4063. Pesq. Agropec. Trop., Goiânia, v. 45, n. 2, p. 241-248, abr./jun. 2015.

TERAO, D.; CARVALHO, A. C. P. P.; BARROSO, T. C. S. Flores tropicais. Brasília: Embrapa Informação Tecnológica, 2005. 225 p. 